\title{
$\beta$ Cell-specific increased expression of calpastatin prevents diabetes induced by islet amyloid polypeptide toxicity
}

Tatyana Gurlo, Safia Costes, Jonathan D. Hoang, Jacqueline F. Rivera, Alexandra E. Butler, and Peter C. Butler

Larry L. Hillblom Islet Research Center, UCLA, David Geffen School of Medicine, Los Angeles, California, USA.

The islet in type 2 diabetes (T2D) shares many features of the brain in protein misfolding diseases. There is a deficit of $\beta$ cells with islet amyloid derived from islet amyloid polypeptide (IAPP), a protein coexpressed with insulin. Small intracellular membrane-permeant oligomers, the most toxic form of IAPP, are more frequent in $\beta$ cells of patients with T2D and rodents expressing human IAPP. $\beta$ Cells in T2D, and affected cells in neurodegenerative diseases, share a comparable pattern of molecular pathology, including endoplasmic reticulum stress, mitochondrial dysfunction, attenuation of autophagy, and calpain hyperactivation. While this adverse functional cascade in response to toxic oligomers is well described, the sequence of events and how best to intervene is unknown. We hypothesized that calpain hyperactivation is a proximal event and tested this in vivo by $\beta$ cell-specific suppression of calpain hyperactivation with calpastatin overexpression in human IAPP transgenic mice. $\beta$ Cell-specific calpastatin overexpression was remarkably protective against $\beta$ cell dysfunction and loss and diabetes onset. The critical autophagy/lysosomal pathway for $\beta$ cell viability was protected with calpain suppression, consistent with findings in models of neurodegenerative diseases. We conclude that suppression of calpain hyperactivation is a potentially beneficial disease-modifying strategy for protein misfolding diseases, including T2D.

\section{Introduction}

The increasing prevalence worldwide of type 2 diabetes (T2D) and its potential consequences, including early death from heart disease, stroke, and kidney failure, are a major healthcare challenge by common consensus. While there are a variety of therapies available to mitigate the hyperglycemia that defines diabetes, as yet there are no therapies targeted to modify the underlying cause of the disease.

Hyperglycemia in T2D is a consequence of $\beta$ cell failure in the setting of insulin resistance. The islet in T2D is characterized by $\beta$ cell dysfunction and loss and islet amyloid composed of islet amyloid polypeptide (IAPP), a protein coexpressed and secreted by $\beta$ cells with insulin (1-3). IAPP expression increases in response to insulin resistance. The islet phenotype in T2D has been reproduced in human IAPP transgenic rodent models $(4,5)$ and is present in other species vulnerable to developing $\mathrm{T} 2 \mathrm{D}$, such as nonhuman primates and cats $(6,7)$. Moreover, vulnerability of a species to develop T2D depends on the propensity of IAPP to form amyloid $(2,3)$. T2D can therefore be classified along with neurodegenerative diseases as a protein misfolding disease. Amyloidogenic proteins share in common the propensity to form membrane-disruptive intracellular toxic oligomers $(8,9)$. The presence of these intracellular oligomers is associated with induction of stress signaling pathways, cellular dysfunction, and gradual attrition of the relevant

Conflict of interest: The authors have declared that no conflict of interest exists.

Submitted: July 19, 2016

Accepted: October 5, 2016

Published: November 3, 2016

Reference information:

JCI Insight. 2016;1(18):e89590

doi:10.1172/ji.insight.89590. cell type $(2,3)$. Calpain hyperactivation has been implicated as a propagator of many of the adverse consequences initiated by formation of toxic protein oligomers (10-17).

Calpains are cysteine proteases that are activated by $\mathrm{Ca}^{2+}$ and constrained temporarily and spatially by the endogenous calpain inhibitor calpastatin (18). In health, calpains facilitate cytoskeletal rearrangements and regulate key signaling pathways. Toxic oligomers of amyloidogenic proteins form in cell membranes that have a phospholipid composition with an electrostatic charge, a feature that favors membrane engagement of the relevant protein $(8,9)$. Once assembled in the membranes, the toxic oligomers act as nonselective ion channels (8), permitting aberrant and sustained $\mathrm{Ca}^{2+}$ signals that are a likely mechanism for calpain hyperactivation. Adverse consequences of sustained calpain hyperactivation include disruption 
of the autophagy/lysosomal pathway $(19,20)$. This pathway is critically important for $\beta$ cell function and survival, particularly in relation to protection against IAPP misfolding (21-23), and has been implicated in $\beta$ cell dysfunction in diabetes (24) and neurodegeneration related to amyloid protein misfolding $(25,26)$.

Given the close resemblance of $\beta$ cell and neuronal cell dysfunction in T2D and neurodegenerative diseases, notably the presence of membrane-permeant toxic oligomers $(27,28)$ and calpain hyperactivation $(14,29)$, we posed the hypothesis that calpain hyperactivation plays a proximal role in $\beta$ cell dysfunction induced by human IAPP (hIAPP) protein misfolding in T2D. To test this hypothesis, we employed a genetic approach to suppress calpain activation in hIAPP transgenic mice by $\beta$ cell-specific increased expression of human calpastatin.

\section{Results}

hIAPP-induced calpain hyperactivation is accompanied by calpastatin deficiency. Calpain hyperactivation mediates proteolysis of target proteins that include the endogenous calpain inhibitor calpastatin (30), thereby amplifying and sustaining calpain induced cellular dysfunction. We previously reported calpain hyperactivation in $\beta$ cells of both humans with T2D and hIAPP transgenic mice by use of the reporter of calpain hyperactivation, increased cleavage of spectrin (14). Since our goal in the current studies was to investigate the potential benefit of suppressing calpain hyperactivation by use of calpastatin, we first addressed the question, does hIAPP-induced calpain hyperactivation lead to a deficit of calpastatin? As with protein misfolding in affected neurons of neurodegenerative diseases, we found a marked deficit of both cytosolic and nuclear calpastatin in islets of hIAPP transgenic mice (hTG mice, Figure 1A) despite increased calpastatin mRNA levels (Figure 1B). We next sought to establish whether suppression of calpain hyperactivation by overexpression of calpastatin would mitigate $\beta$ cell dysfunction and loss initiated by hIAPP oligomers.

Overexpression of human calpastatin suppresses calpain hyperactivation and markedly delays the onset of diabetes in human IAPP transgenic mice. To test the hypothesis that calpain hyperactivation propagates hIAPP-induced $\beta$ cell dysfunction and loss, we generated hTG mice (31) with $\beta$ cell-specific overexpression of human calpastatin (hTG:hCAST mice). By immunohistochemistry, human calpastatin expression was confirmed in $\beta$ cells in both the cytoplasm and the nucleus (Figure 2A). By Western blotting, human calpastatin expression was confirmed in the cytosolic and nuclear fractions of islet lysates (Supplemental Figure 1; supplemental material available online with this article; doi:10.1172/jci.insight.89590DS1). Note that gels in Figure 2B and Supplemental Figure 1 were exposed for much less time than those in Figure 1A to avoid burning the gels in the hCAST lanes, but endogenously expressed calpastatin was confirmed in Figure 1A. Transgenic overexpression of calpastatin suppressed hIAPP-induced calpain hyperactivation, as demonstrated by reduced cleavage of spectrin (Figure 2, B and C). Suppression of calpain hyperactivation in hTG:hCAST mice preserved islet insulin levels (Supplemental Figure 2A) without significant effect on levels of monomeric IAPP (Supplemental Figure 2B). To establish whether preservation of islet insulin content translates into protection against diabetes, we measured fasting blood glucose starting from 6 weeks of age. In WT mice and WT mice expressing human calpastatin (WT:hCAST mice), blood glucose remained normal (data not shown) for the duration of the experiment (age 6-24 weeks). As expected, hTG mice developed diabetes at between 9 and 12 weeks of age (Figure 3A) (31). Suppression of calpain hyperactivation had a striking effect to protect hTG mice from developing diabetes (Figure 3, A and B). At 12 weeks of age, the fasting blood glucose level was $280 \pm 29 \mathrm{mg} / \mathrm{dl}$ in hTG group, while it remained within a normal range at $79 \pm 8$ $\mathrm{mg} / \mathrm{dl}$ in hTG:hCAST mice (Figure 3C). There was no difference in body weight between hTG and hTG:hCAST mice (Supplemental Figure 3). This protection against diabetes was accomplished by attenuation of hIAPP-induced $\beta$ cell apoptosis, which thus preserved $\beta$ cell mass (Figure 3, D and E). At 12 weeks of age, $\beta$ cell mass in hTG mice was markedly decreased compared with WT mice $(0.6 \pm 0.1 \mathrm{mg}$ vs. $2.8 \pm 0.2 \mathrm{mg}$, $P<0.001)$ but relatively preserved in hTG:hCAST mice $(1.9 \pm 0.2 \mathrm{mg}, P<0.001 \mathrm{vs}$. hTG). As expected, $\beta$ cell apoptosis was increased in hTG mice compared with control groups (Figure 3E) but was attenuated in hTG:hCAST mice compared with hTG mice $(0.31 \% \pm 0.11 \%$ vs. $0.81 \% \pm 0.13 \%$, respectively; $P<0.001)$. $\beta$ Cell replication was comparably low in hTG:hCAST and WT mice (Figure 3F), affirming that the $\beta$ cell mass in hTG mice preserved by calpastatin overexpression was due to decreased $\beta$ cell apoptosis rather than increased $\beta$ cell replication. Having established that calpain hyperactivation plays a key role in hIAPP-induced $\beta$ cell loss, we sought to investigate the mechanisms by which calpain propagates hIAPP toxicity.

hIAPP-induced endoplasmic reticulum stress and oxidative stress are attenuated by suppression of calpain hyperactivation. The endoplasmic reticulum and mitochondrial networks are functionally and morphologically 
A

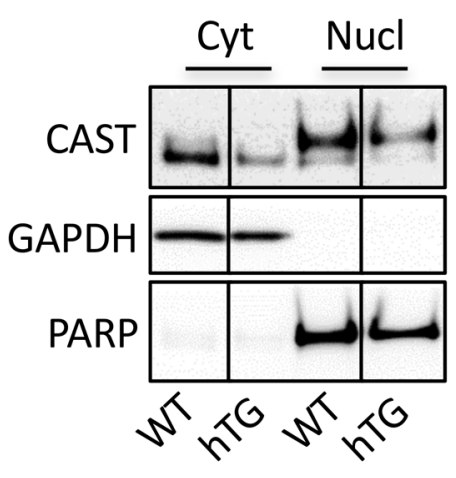

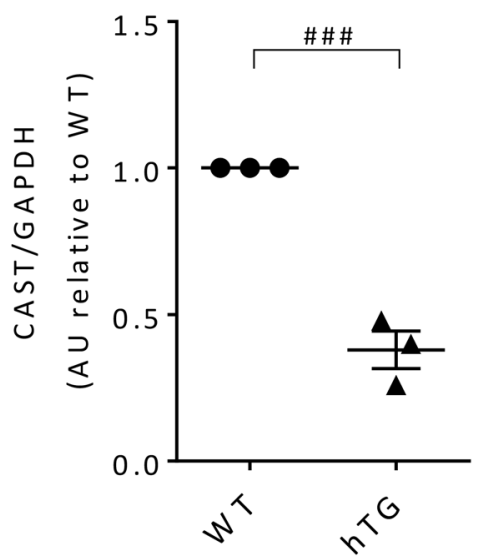

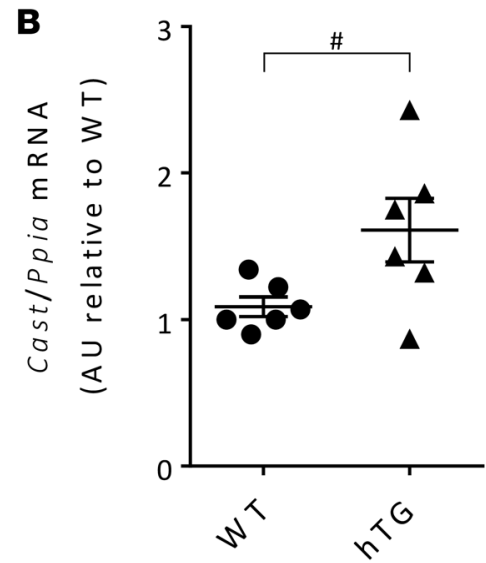

Figure 1. Calpastatin levels in islets from mice overexpressing human IAPP. (A) Representative Western blot (from 1 of 3 independent experiments performed) reflecting calpastatin protein levels in cytosolic and nuclear enriched fractions of islet lysates obtained from 9 -week-old WT (average fasting blood glucose, $76.8 \pm 6.5 \mathrm{mg} / \mathrm{dl}$ ) and human IAPP transgenic mice (hTG; average fasting blood glucose, $79.3 \pm 7.6 \mathrm{mg} / \mathrm{dl}$ ). GAPDH and PARP were used as loading controls for cytosolic and nuclear fractions, respectively. The lanes were run on the same gel but were noncontiguous. The graph shows quantification of calpastatin levels in the cytosolic fraction. (B) mRNA levels of calpastatin in islets from 9-week-old WT mice (average fasting blood glucose, $65.1 \pm$ $4.3 \mathrm{mg} / \mathrm{dl}$ ) and hTG mice (average fasting blood glucose, $72.0 \pm 3.8 \mathrm{mg} / \mathrm{dl}$ ) were assessed by quantitative RT-PCR. Data are expressed as mean \pm SEM; $n=$ 3 (A) and $n=6$ (B) for each group; ${ }^{\#} P<0.05,{ }^{\# \#} P<0.001,2$-tailed Student's $t$ test.

related (32). The interdependence of endoplasmic reticulum stress, mitochondrial dysfunction, and oxidative damage has been increasingly appreciated as an adverse cycle in protein misfolding diseases (33) Therefore, it is perhaps not surprising that endoplasmic reticulum stress and disruption of mitochondrial network integrity and function, together with the consequent oxidative stress, are commonly reported in target tissues of misfolded protein diseases, including $\beta$ cells in T2D $(2,3)$. To investigate if calpain hyperactivation is upstream of and/or propagates this adverse cycle induced by IAPP toxicity, we investigated the effect of increased $\beta$ cell expression of calpastatin on endoplasmic reticulum stress, oxidative stress, and its consequence, DNA damage.

To evaluate endoplasmic reticulum stress, we quantified Ddit3 mRNA levels, CCAAT/-enhancer-binding protein homologous protein (CHOP), and the proportion of $\beta$ cells with detectable nuclear CHOP. Suppression of calpain hyperactivation attenuated the increase in Ddit 3 mRNA levels induced by hIAPP (Figure 4A). $\beta$ Cell endoplasmic reticulum stress, revealed by an increase in CHOP nuclear translocation, was confirmed in hTG mice (34) but markedly suppressed by calpastatin overexpression $(1.13 \% \pm 0.24 \%$ vs. $0.27 \% \pm 0.13 \%$ in hTG and hTG:hCAST mice, respectively, $P<0.01$; Figure 4 , B and C). Moreover, BCL-2 homology domain 3-only (BH3-only) protein Bim, shown to be central mediator of the endoplasmic reticulum stress-induced apoptosis, was, as expected, increased in islets from hTG mice relative to control mice (35), but this increase was prevented in hTG:hCAST mice (2.54 \pm 0.37 vs. $1.45 \pm 0.19$ in hTG and hTG:hCAST mice, respectively, $P<0.01$; Figure 4D).

To evaluate oxidative stress, we investigated expression of the transcription factor Nrf2 (nuclear factor-erythroid 2 p45-related factor 2, also known as $\mathrm{Nfe} 2 \mathrm{l2}$ ) and Nrf2 target genes that are an important defense against oxidative stress (36). mRNA of Nfe2l2 and its targets Hmoxl (heme oxygenase 1, also known as $\mathrm{HO}-1)$ and $N q o 1(\mathrm{NAD}(\mathrm{P}) \mathrm{H}$-quinone oxidoreductase) was increased in islets of hTG mice, revealing hIAPP-induced oxidative stress (Figure 5A) and also, interestingly, partially in WT:hCAST mice. In the context of hIAPP toxicity in hTG mice, the Nrf2 pathway was suppressed by calpastatin in hTG:hCAST mice, implying that hIAPP-induced oxidative stress is overcome by suppression of calpain hyperactivation (Figure $5 \mathrm{~A})$. These data were consistent with the presence of increased $\beta$ cell DNA damage detected by histone H2AX phosphorylation (P-H2AX), a marker of double-strand break repair (37), in hTG mice compared with WT controls $(0.94 \% \pm 0.18 \%$ vs. $0.31 \% \pm 0.05 \%, P<0.001$; Figure $5 \mathrm{~B})$. Calpastatin-mediated suppression of calpain hyperactivation suppressed the hIAPP-induced DNA damage $(0.22 \% \pm 0.06 \%, P<0.001$ vs. hTG; Figure 5, B and C), further supporting the importance of calpain hyperactivation in oxidative stress.

In conclusion, hIAPP-mediated $\beta$ cell endoplasmic reticulum stress and oxidative stress is induced and/ or propagated, at least in part, through the actions of calpain hyperactivation. To date, while several strategies 


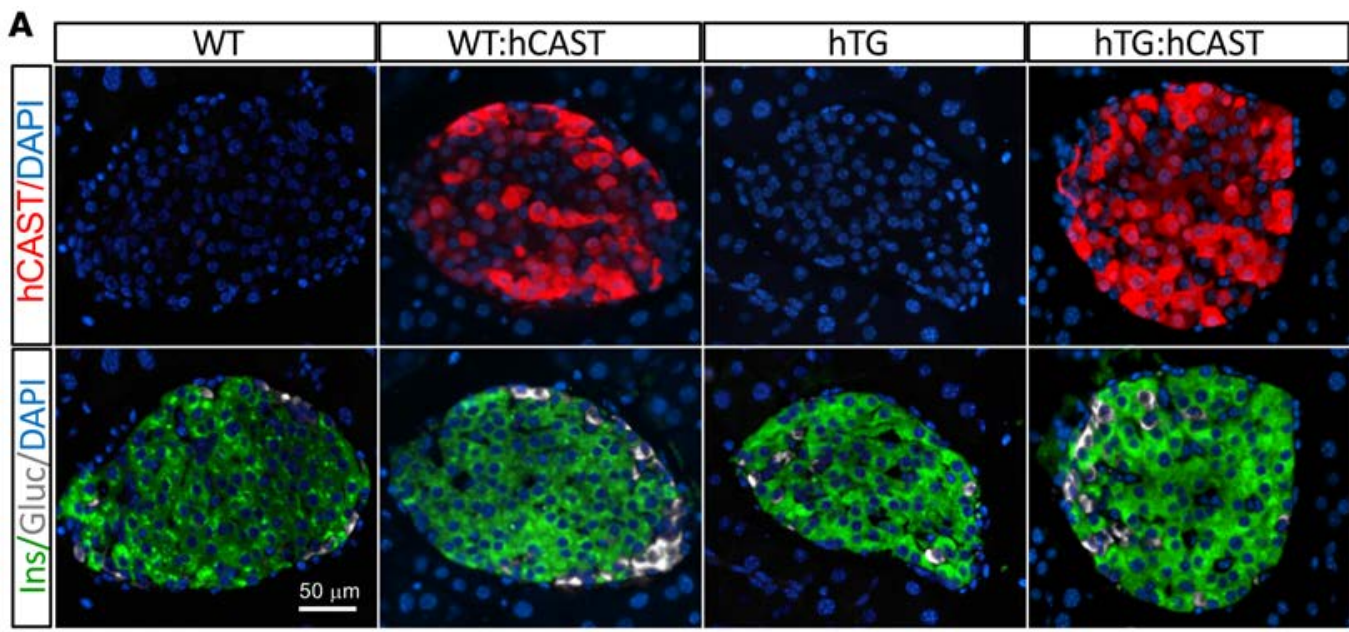

B

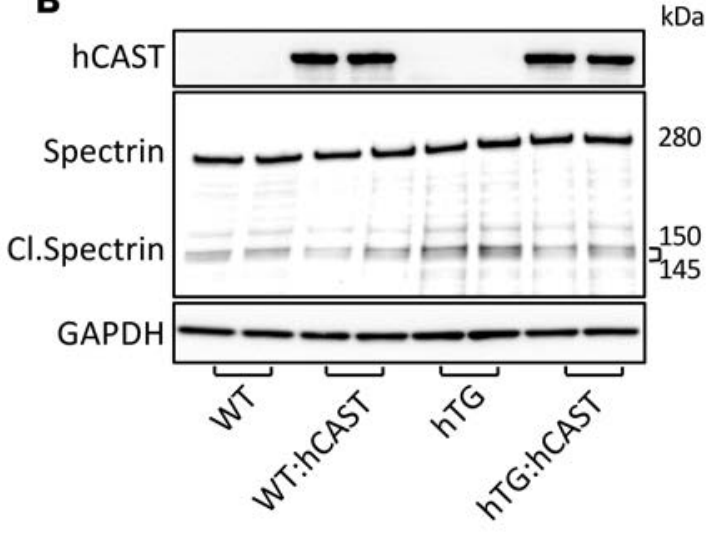

C

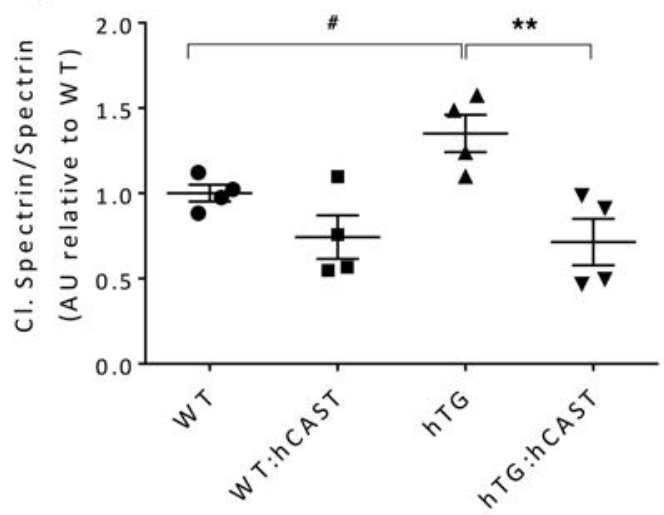

Figure 2. Calpastatin overexpression in $\beta$ cells results in inhibition of calpain hyperactivity in hTG mice. (A) Representative immunofluorescence images of islets from 8-week-old WT, WT:hCAST, hTC, and hTC:hCAST mice stained for human calpastatin (red), insulin (green), glucagon (white), and nuclei (blue, DAPI). Original magnification, $\times 20$. Scale bar: $50 \mu \mathrm{m}$. (B) Representative Western blot (from 1 of 2 independent experiments performed) reflecting calpain activity in islet samples obtained from 9-week-old WT, WT:hCAST, hTC, and hTC:hCAST mice, with average fasting blood glucose levels of 76 and 65, 51 and 56, 75 and 94 , and 58 and $99 \mathrm{mg} / \mathrm{dl}$, respectively. Calpain activity was assessed by spectrin cleavage (145- and 150-kDa cleaved fragments). GAPDH was used as loading control; calpastatin is shown for confirmation of its transgenic expression in hCAST groups. (C) Quantification of cleaved spectrin versus total spectrin $(280 \mathrm{kDa})$. Data are expressed as mean $\pm \mathrm{SEM} ; n=4$ for each group; ${ }^{* *} P<0.01$ versus $\mathrm{hTC}$; $P<0.05$ versus WT, 1 -way ANOVA followed by Fisher's LSD post-hoc test.

have been employed that partially ameliorate toxicity of hIAPP, including deletion of CHOP (35), these interventions have generally been, at best, partially effective. Based on genetic studies, the most compelling target that has emerged to date is the autophagy/lysosomal pathway (21-23). As calpain hyperactivation induced by other amyloidogenic proteins is known to disrupt the autophagy/lysosomal pathway $(19,20)$, we next investigated the effect of suppression of calpain hyperactivation on the autophagy/lysosomal pathway in hTG mice.

Suppression of calpain hyperactivation attenuates the hIAPP-induced defect in the autophagy/lysosomal pathway. The scaffold protein p62 (sequestosome 1, also known as SQSTM1) binds polyubiquitinated misfolded proteins via a ubiquitin-binding UBA domain and assembles them within autophagosomes for subsequent degradation by lysosomes (38). Since p62 and its ubiquitinated cargo are delivered together into the autophagy/lysosomal pathway for degradation, accumulation of p62 signifies a defect in this pathway of protein and organelle recycling. As previously reported in hTG mice, islet p62 levels were markedly increased compared with WT $(21,39)$ (Figure 6, A and C), and p62 accumulation was evident as immunoreactive inclusions in $\beta$ cells (Figure 6E). p62 levels were restored to near normal by calpastatin-mediated suppression of calpain hyperactivation (Figure 6C), an effect that was not attributable to decreased p62 gene expres- 
A

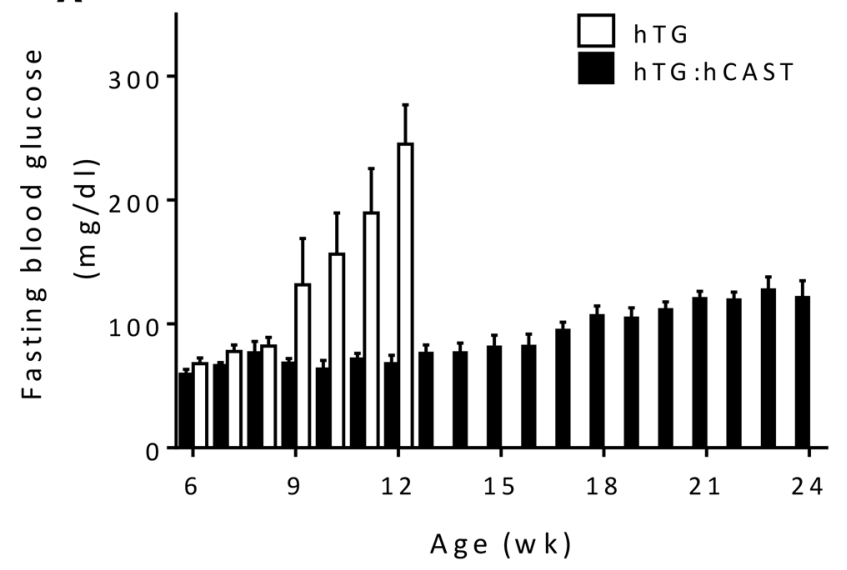

C

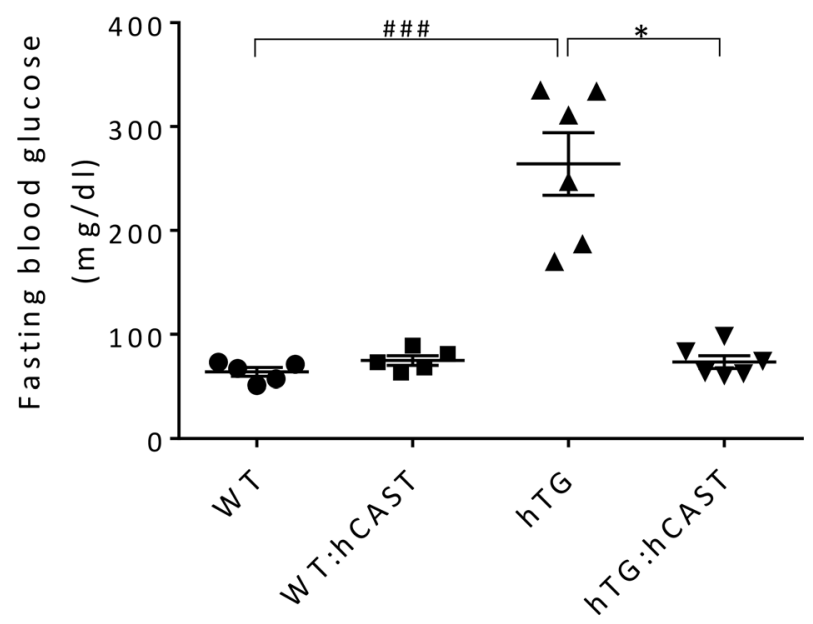

E

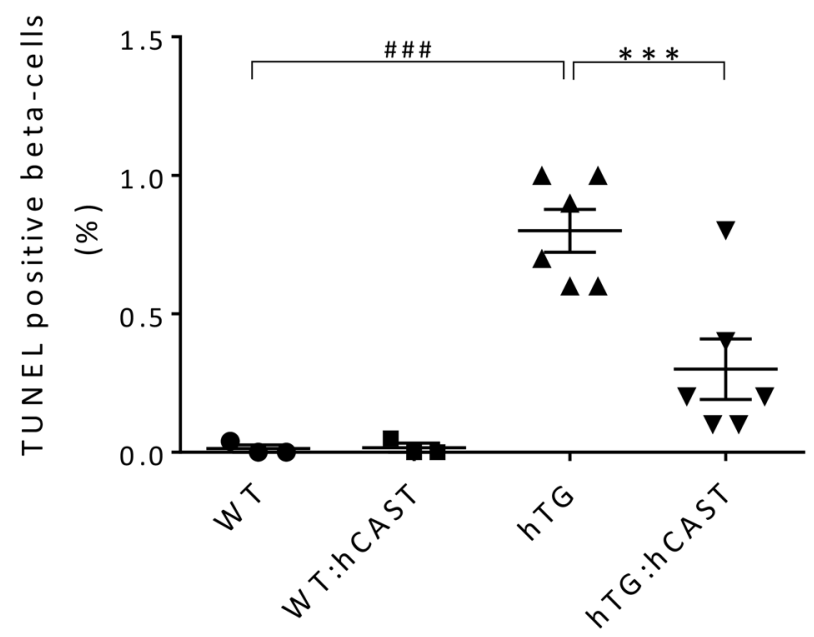

B

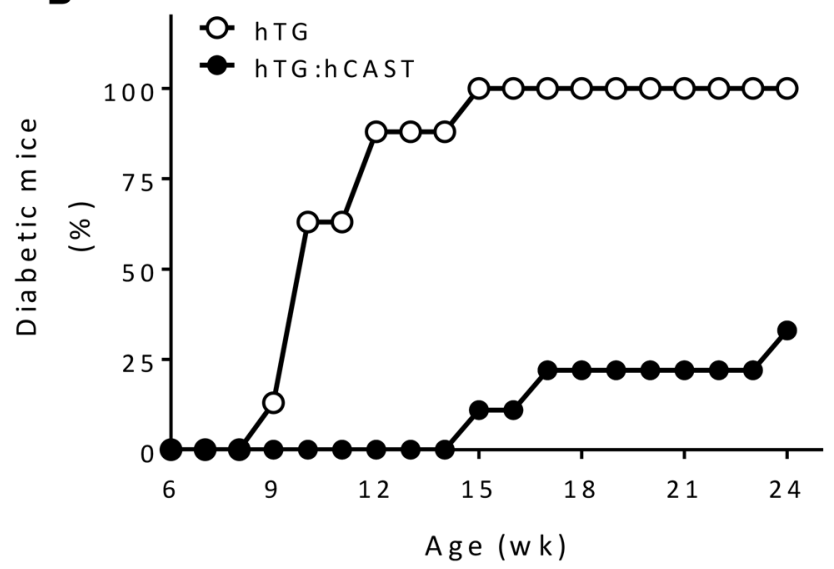

D

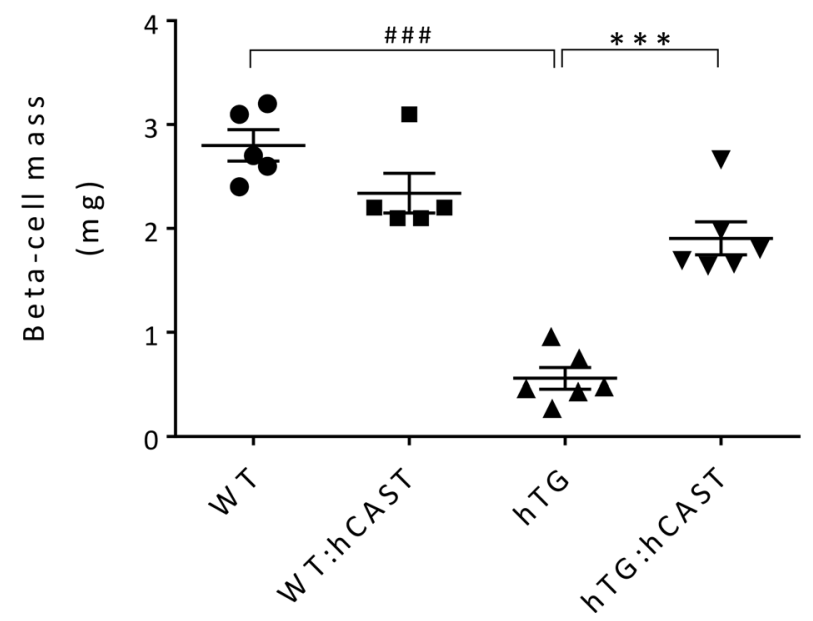

$\mathbf{F}$

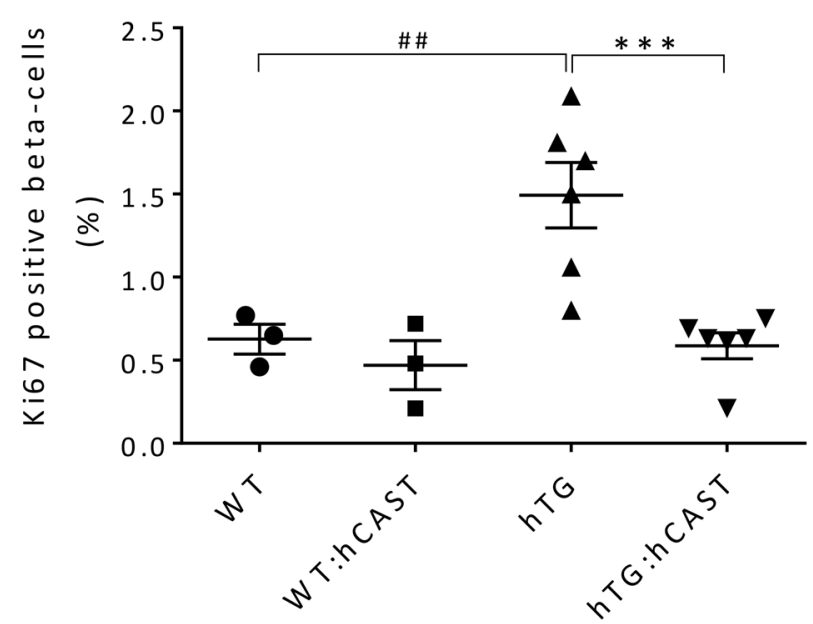

Figure 3. Calpastatin overexpression in $\boldsymbol{\beta}$ cells protects hTG mice from diabetes. (A) Weekly fasting blood glucose ( $n=4-9$ per time point) and (B) frequency of diabetes in hTC and hTC:hCAST mice. (C) Fasting blood glucose and (D) $\beta$ cell mass were measured in 12-week-old mice; WT ( $n=5$ ), WT:hCAST $(n=5)$, hTG $(n=6)$, and hTC:hCAST $(n=6)$. (E) $\beta$ Cell apoptosis was assessed by TUNEL and (F) $\beta$ cell proliferation was assessed by Ki67 immunofluorescence staining in 12-week-old mice; WT $(n=3)$, WT:hCAST $(n=3)$, hTG $(n=6)$, and hTG:hCAST $(n=6)$. Data are expressed as mean \pm SEM; ${ }^{*} P<$ $0.05,{ }^{* *} P<0.001$ vs. hTG; ${ }^{\#} P<0.01,{ }^{\# \#} P<0.001$ vs. WT; 1-way ANOVA followed by Fisher's LSD post-hoc test. 
sion (Figure 6D). The formation of autophagosomes is mediated by microtubule-associated protein 1 light chain 3 (LC3) after cleavage (LC3-I) and lipidation to LC3-II (40). Consistent with impaired clearance of p62 through the autophagy/lysosomal pathway, LC3-II levels, a marker for autophagosome number, were increased in hTG mice, implying accumulation of autophagosomes (Figure 6, A and B). This was partially overcome by calpastatin-mediated suppression of calpain activation. Although the mRNA levels of Atg5, a key regulator of autophagosome formation (41), were increased, the protein levels of Atg 5 were decreased in hTG mice relative to controls $(P<0.001)$, uncovering an apparent defect in autophagosome formation in hTG mice that is partially overcome by calpastatin overexpression (Supplemental Figure 4).

In addition to accumulation of p62, another indicator that clearance of misfolded aggregate-prone proteins by the autophagy/lysosomal pathway is insufficient is the accumulation of polyubiquitinated proteins, a characteristic of $\beta$ cells in humans with T2D and in hIAPP transgenic rodent models (42). Calpastatin-mediated suppression of calpain hyperactivation decreased the accumulation of ubiquitinated proteins in hTG mice (Supplemental Figure 5). Taken together, these findings reveal that the defect in the autophagy/lysosomal pathway induced by hIAPP toxicity is mediated, at least in part, by calpain hyperactivation.

\section{Discussion}

$\beta$ Cell failure in T2D shares much in common with hippocampal cells in Alzheimer's disease, dopaminergic neurons in Parkinson's disease, and motor neurons in Huntington's disease. The affected cell types in these diseases of aging are characterized by progressive dysfunction and attrition, with a shared molecular signature of cellular stress, calpain hyperactivation, mitochondrial network disruption, DNA damage, and accumulation of polyubiquitinated misfolded proteins (2). They also share in common that the vulnerable cells in each disease express amyloidogenic proteins that, under the conditions of the various disease states, form membrane-disruptive toxic oligomers that play an important role in cellular dysfunction $(2,28)$. In contrast, the extracellular amyloid deposits of the same proteins, while more conveniently detected and therefore often used in the pathological diagnosis of the diseases, are less toxic. This may explain why therapeutic efforts to reduce the burden of extracellular amyloid have generally been unsuccessful in modifying the disease course in protein misfolding diseases (43).

An alternative approach is to interrupt the cytotoxic pathways that are activated by the intracellular membrane-permeant toxic oligomers. Calpain hyperactivation has been attributed to aberrant $\mathrm{Ca}^{2+}$ signaling caused by dysregulated membrane leakage induced by toxic oligomers (14). While development of effective calpain inhibitors is an area of focus by pharmaceutical companies, the potential therapeutic benefit of attenuating calpain hyperactivation has been tested experimentally by use of the endogenous calpain inhibitor, calpastatin. By use of this strategy, we accomplished a remarkable degree of protection against human IAPP $\beta$ cell toxicity and delayed diabetes.

Since most previously established adverse consequences of hIAPP toxicity were ameliorated by increased calpastatin expression and, at least partially, by its role in calpain suppression, our findings imply that calpain hyperactivation plays a proximal and amplifying role in human hIAPP toxicity. Prominent among these beneficial actions was the restoration of the autophagy/lysosomal pathway, a pathway known to be critical in defending $\beta$ cells against human hIAPP toxicity (21-23) and previously established as disrupted by calpain hyperactivation $(19,20,39)$. The autophagy/lysosomal pathway is critical in protecting long-lived cells vulnerable to protein misfolding not only by clearing and degrading misfolded amyloidogenic proteins, but also by maintaining the mitochondrial network through mitophagy (44).

Mitochondrial network disruption and dysfunction with increased ROS generation and DNA damage are prominent in protein misfolding diseases and are characteristic of $\beta$ cells in both humans with T2D and hIAPP transgenic models of T2D $(27,37)$. This disruption might be mediated directly by the membrane-permeable toxic oligomers, by hyperactivated calpains $(45,46)$, and by $\mathrm{Ca}^{2+}$ overload as a result of dysregulated ER Ca ${ }^{2+}$ leakage (47), particularly if the latter were to occur at the mitochondrial endoplasmic reticulum membrane interface. The proapoptotic BH3-only Bcl-2 family member Bim that is increased by hIAPP toxicity not only contributes to mitochondrial membrane disruption (48), but may also inhibit autophagy (49). Of interest, while Ddit3 (CHOP) deletion did not attenuate the hIAPP-induced Bim increase (35), suppression of calpain hyperactivation did, implying that hIAPP-induced Bim augmentation is downstream of hyperactive calpain. The fidelity and function of the mitochondrial network is particularly critical in pancreatic $\beta$ cells, not only for cell viability, but also their function. Tight linkage between glycolytic flux and oxidative phosphorylation is necessary to link the extracellular glucose concentration with regulated insulin secretion (50). When 
A

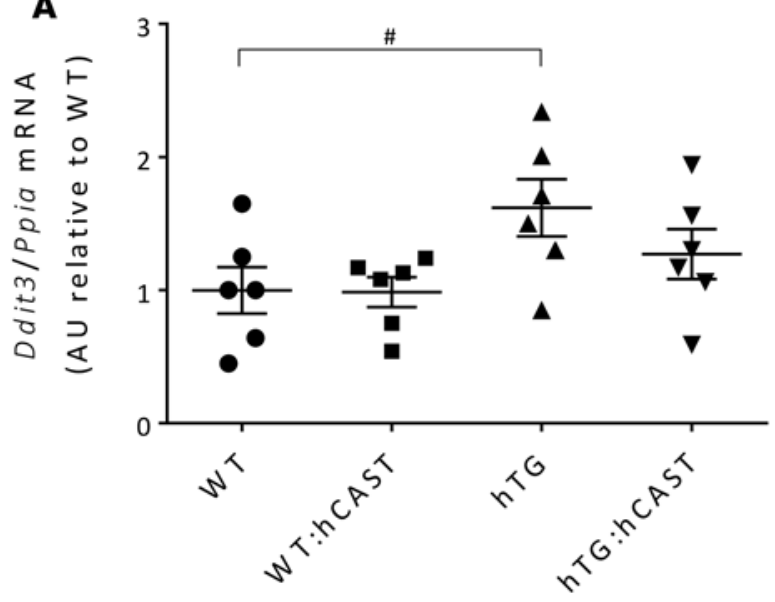

B

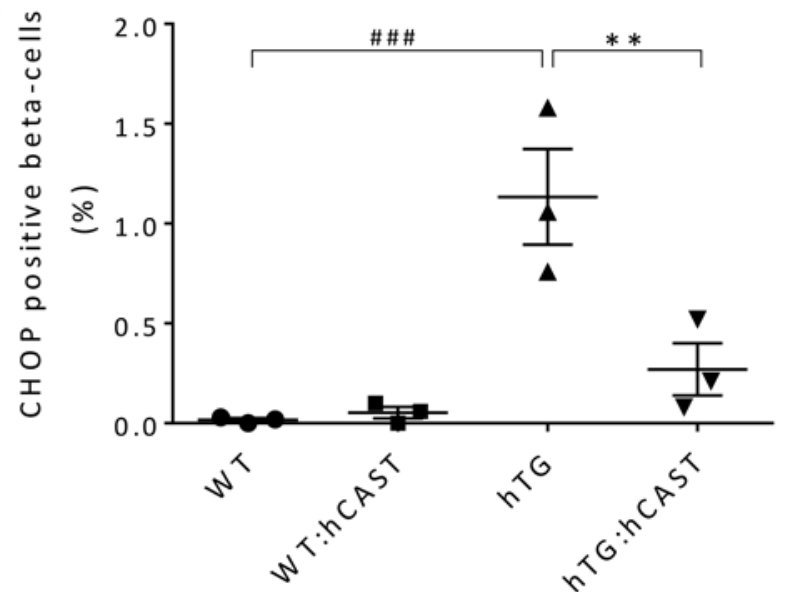

C

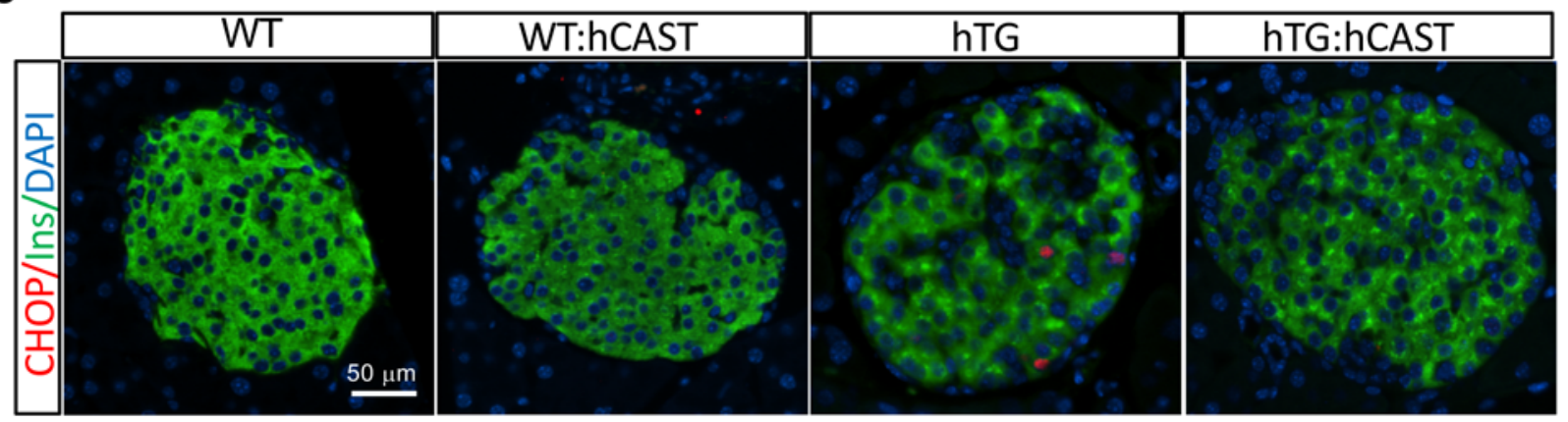

D
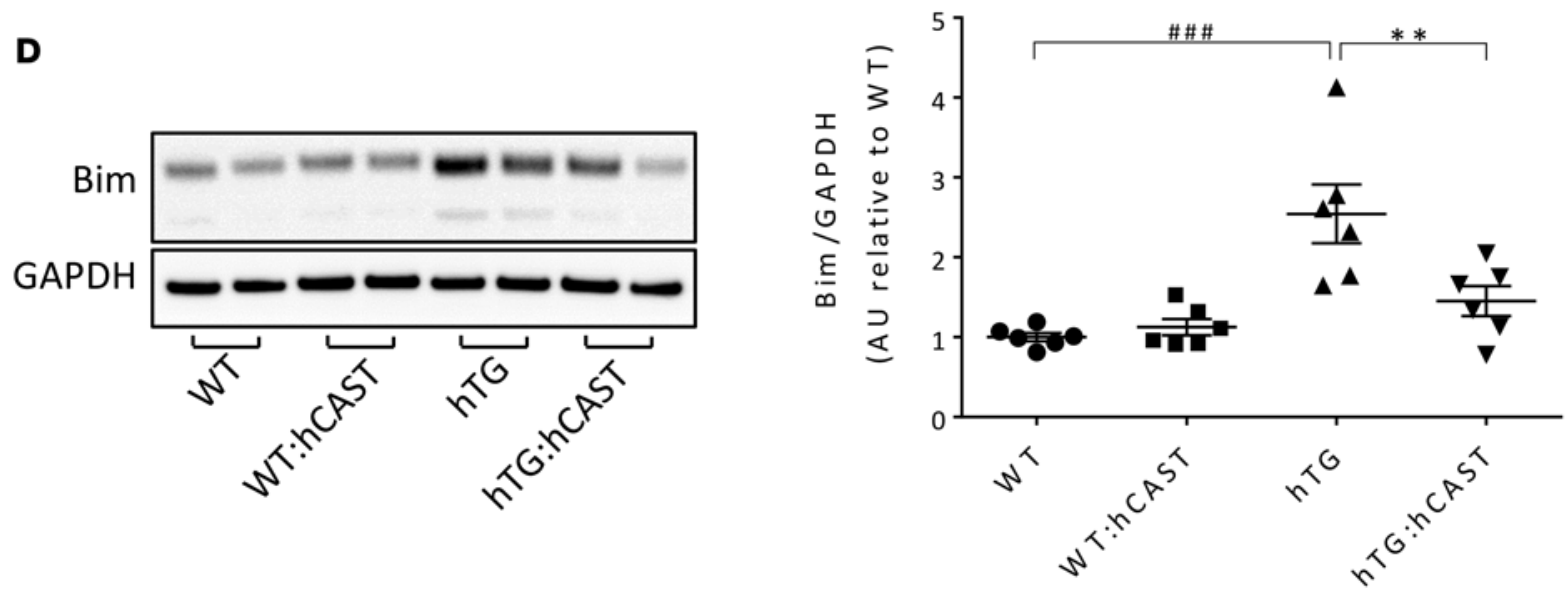

Figure 4. hCAST overexpression in $\boldsymbol{\beta}$ cells results in the attenuation of hIAPP-induced ER stress. (A) Ddit3 (CHOP) mRNA levels were measured by RT-qPCR in islets from 9-week-old WT, WT:hCAST, hTG, and hTG:hCAST mice, with average fasting blood glucose levels of 65.1 $\pm 4.3,77.2 \pm 3.5$, $72.0 \pm 3.8$, and $70.1 \pm 4.1 \mathrm{mg} / \mathrm{dl}$, respectively; $n=6$ for all groups. (B) Frequency of $\beta$ cells containing nuclear CHOP was assessed in 9-week-old WT, WT:hCAST, hTG, and hTG:hCAST mice, with average fasting blood glucose levels of 75.0 $\pm 2.6,79.3 \pm 6.9,76.7 \pm 7.2$, and 74.7 \pm 2.0 mg/dl, respectively; $n=3$ for each group. (C) Representative immunofluorescence images of islets from 8- to 9-week-old mice stained for CHOP (red), insulin (green), and nuclei (blue, DAPI); staining was performed in 3 mice per group. Original magnification, $\times 20$. Scale bar: $50 \mu \mathrm{m}$. (D) Protein levels of Bim assessed by Western blot in islets from 9-week-old mice. Presented Western blot is from 1 of 3 independent experiments performed; quantification of the extralong isoform of $\mathrm{Bim}\left(\mathrm{Bim}_{\mathrm{EL}}\right.$ ) is shown, $n=6$ for each group. Average fasting blood glucose levels were $81.7 \pm 4.7,78.5 \pm 6.2,81.2 \pm 3.3$ and $66.8 \pm 3.7$ mg/dl in WT, WT:hCAST, hTG, and hTG:hCAST mice, respectively. Data are expressed as mean \pm SEM; ${ }^{* *} P<0.01$ vs. hTG; ${ }^{*} P<0.05$, \#\#\# $P 0.001$ vs. WT; 1-way ANOVA followed by Fisher's LSD post-hoc test. 
A

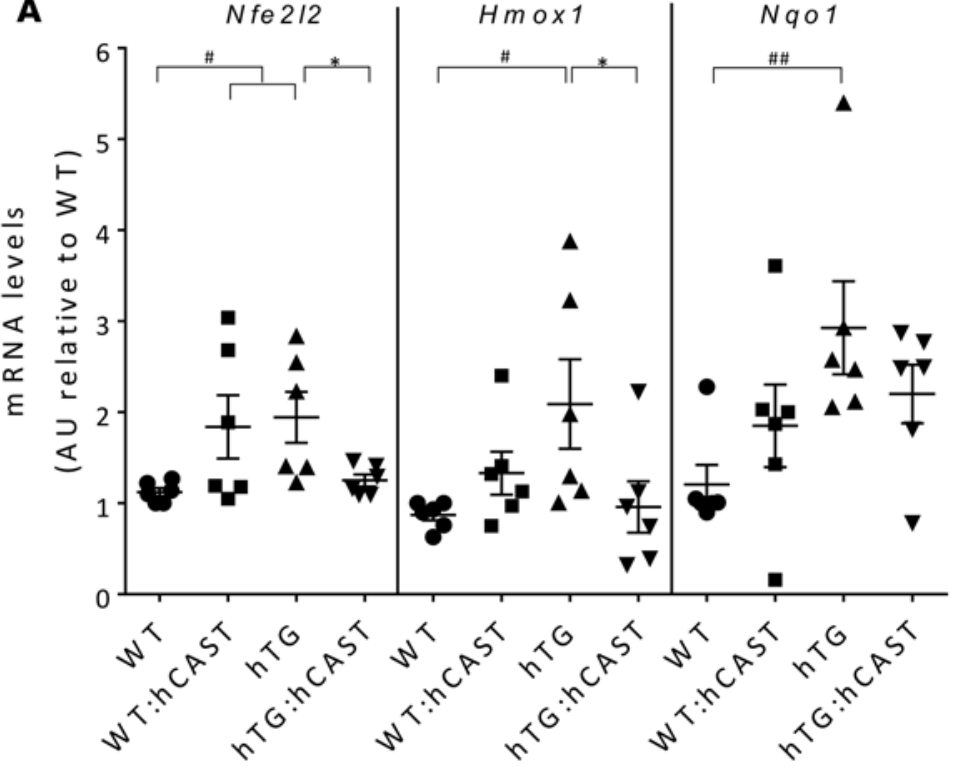

B

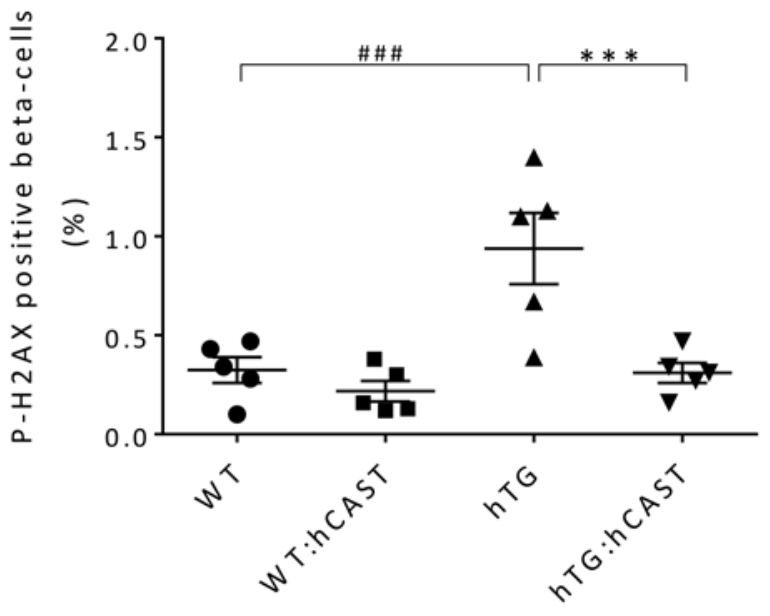

Figure 5. Calpastatin overexpression in $\beta$ cells attenuates oxidative stress and is protective against DNA damage. (A) Antioxidant enzyme mRNA levels measured by RT-qPCR; $n=6$ for all groups; see the legend of Figure 4A for fasting blood glucose levels in mice from each group. (B) Quantification of the frequency of $\beta$ cells positive for phospho- $\mathrm{H} 2 \mathrm{AX}$ assessed by immunofluorescence. Immunostaining was performed in 5 mice per group, with average fasting blood glucose levels of $75.0 \pm 2.7,78.8 \pm 5.8,79.0 \pm 4.4$, and $72.8 \pm 2.2 \mathrm{mg} / \mathrm{dl}$ in WT, WT:hCAST, hTC, and hTG:hCAST mice, respectively. Data are expressed as mean \pm SEM; $n=5$, for each group; ${ }^{*} P<0.05$, ${ }^{* * *} P<0.001$ vs. hTC; ${ }^{*} P<0.05,{ }^{* \#} P<0.01$, $\# \# \#<0.001$ vs. WT; 1 -way ANOVA followed by Fisher's LSD post-hoc test. (C) Representative immunofluorescence images of islets from 9-week-old WT, WT:hCAST, hTC, and hTC:hCAST mice stained for phospho-H2AX (red), insulin (green), and nuclei (blue, DAPI). Original magnification, $\times 20$. Scale bar: $50 \mu \mathrm{m}$.

this linkage is disrupted, $\beta$ cell function is compromised, leading to the superimposition of glucotoxicity, amplified ER stress, and an increased burden of protein misfolding, each adding to further mitochondrial network disruption $(51,52)$.

Taking the available findings together, we propose a model for $\beta$ cell dysfunction and loss induced by hIAPP misfolding (Figure 7). As previously reviewed, the conditions that favor hIAPP misfolding and toxic oligomer formation are also the known risk factors for $\mathrm{T} 2 \mathrm{D}$, including insulin resistance and aging and, possibly, a low innate $\beta$ cell mass (53). In humans, after the period of rapid expansion in $\beta$ cell mass in the postnatal period, there is a wide range in $\beta$ cell mass among individuals (54). Since $\beta$ cell mass has a limited capacity to adaptively expand in adults $(55,56)$, the interaction between a low innate $\beta$ cell mass and insulin resistance may lead to an expression rate of IAPP per $\beta$ cell that exceeds the capacity for clearance of misfolded proteins, potentially initiating toxic oligomer formation in a few most vulnerable $\beta$ cells. Once toxic membrane-permeant oligomers form, we postulate that aberrant $\mathrm{Ca}^{2+}$ release provokes calpain hyperactivation, an outcome known to compromise the autophagy/lysosomal pathway and thus mitophagy, both of which have been reported in human islets in T2D (14, 57). A compromised mitochondrial network leads to both $\beta$ cell dysfunction by uncoupling glycolysis from mitochondrial ATP production and 
A

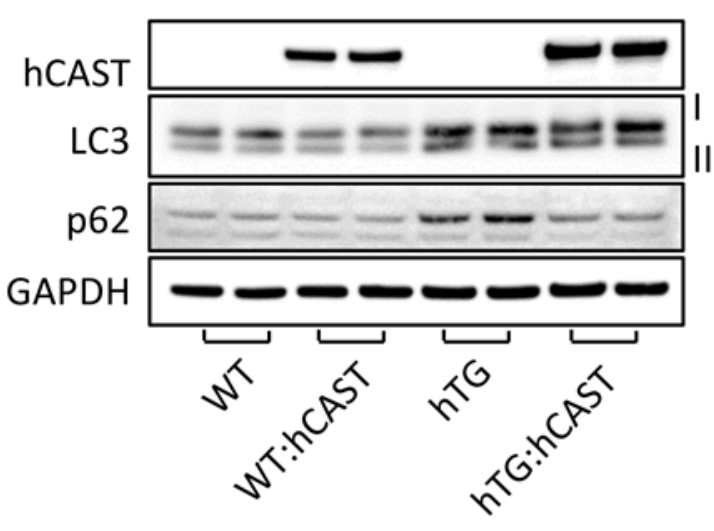

C

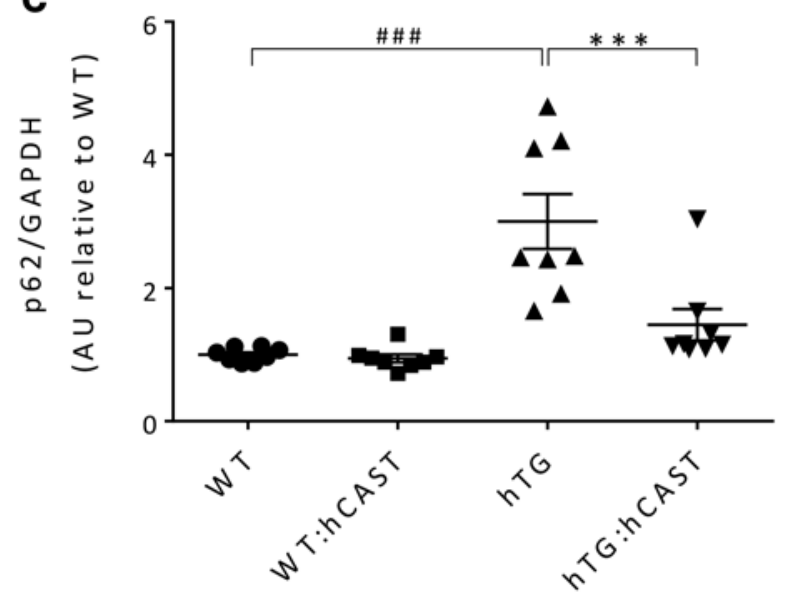

B

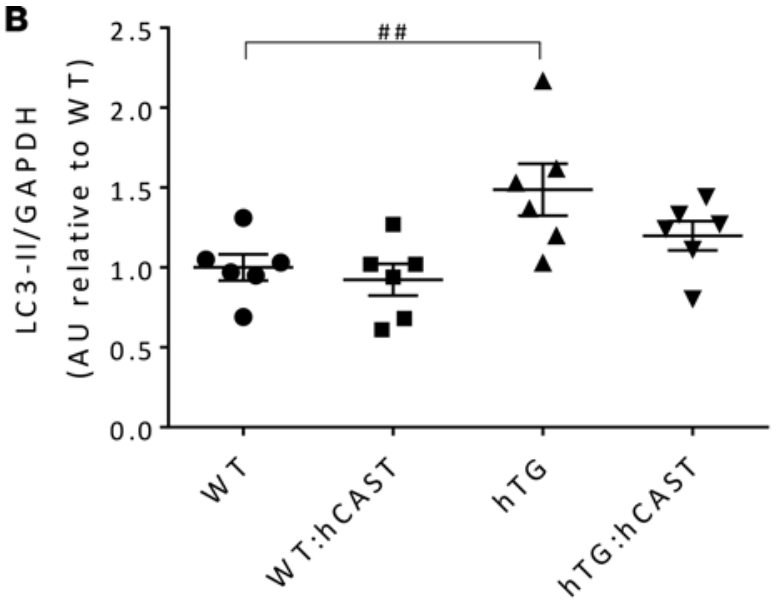

D

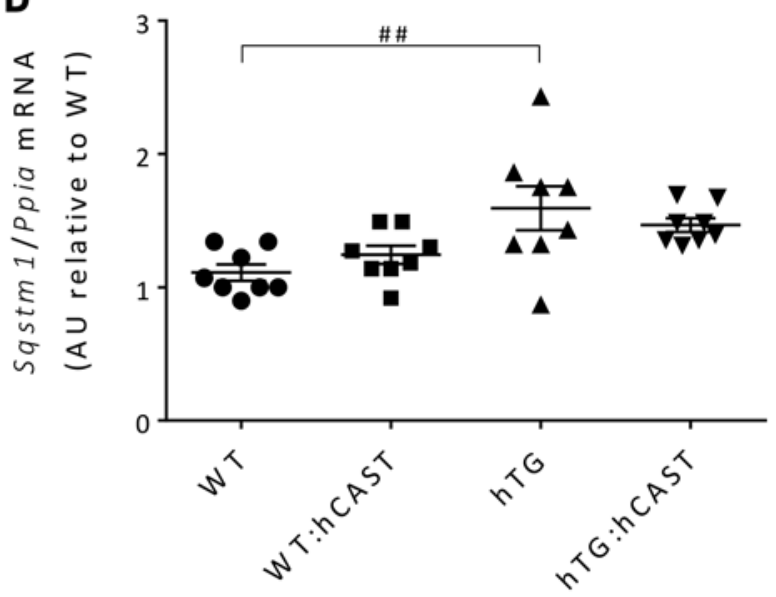

E

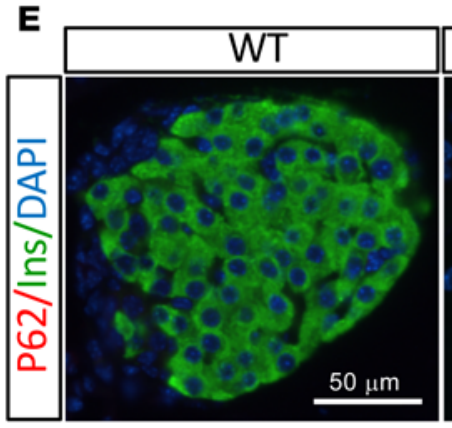

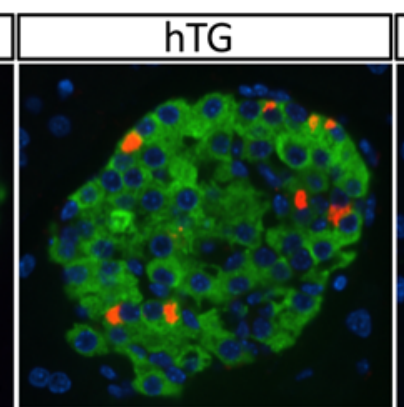

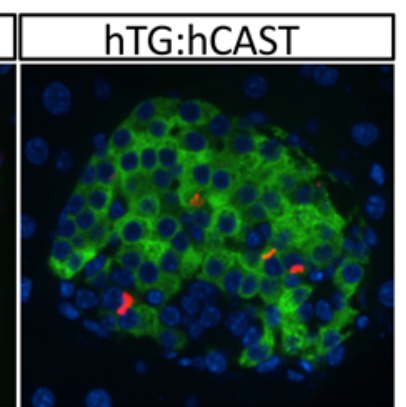

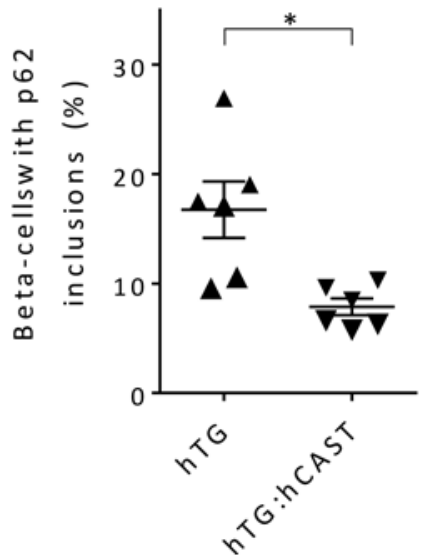

Figure 6. The defect in the autophagy/lysosomal pathway in $\beta$ cells from hTC mice is attenuated by the overexpression of calpastatin. (A) The protein levels of LC3-II and p62 were assessed by Western blotting using islet lysates obtained from 9-week-old WT, WT:hCAST, hTG, and hTC:hCAST mice, with average fasting blood glucose of 64 and 76, 96 and 71, 95 and 89,68 and $62 \mathrm{mg} / \mathrm{dl}$, respectively. Representative Western blot of 3 independent experiments performed. GAPDH was used as loading control, human calpastatin is shown to confirm its transgenic expression in hCAST groups. (B) Quantification of LC3-II protein levels; $n=6$ for all groups. (C) Quantification of p62 protein levels, $n=8$ for all groups. (D) Sqstm1 (p62) mRNA levels were measured by RT-qPCR, $n=6$ for each group; see the legend of Figure 4A for fasting blood glucose levels in mice from each group. (E) Representative immunofluorescence images of islets from 8-week-old WT, hTG, and hTC:hCAST mice stained for p62 (red), insulin (green), and nuclei (blue, DAPI); staining was performed in 6 mice per group. Scale bar: $50 \mu \mathrm{m}$. The graph shows the frequency of $\beta$ cells containing p62 inclusions in islets from 8- to 12-week-old hTC and hTC:hCAST mice. Data are expressed as mean \pm SEM; $n=6,{ }^{*} P<0.05,{ }^{* * *} P<0.001$ vs. hTC; ${ }^{\# \# P<0.01, ~ \# \# \# P<}$ 0.001 vs. WT; 1-way ANOVA followed by Fisher's LSD post-hoc test (B-D); 2-tailed Student's $t$ test (E). 


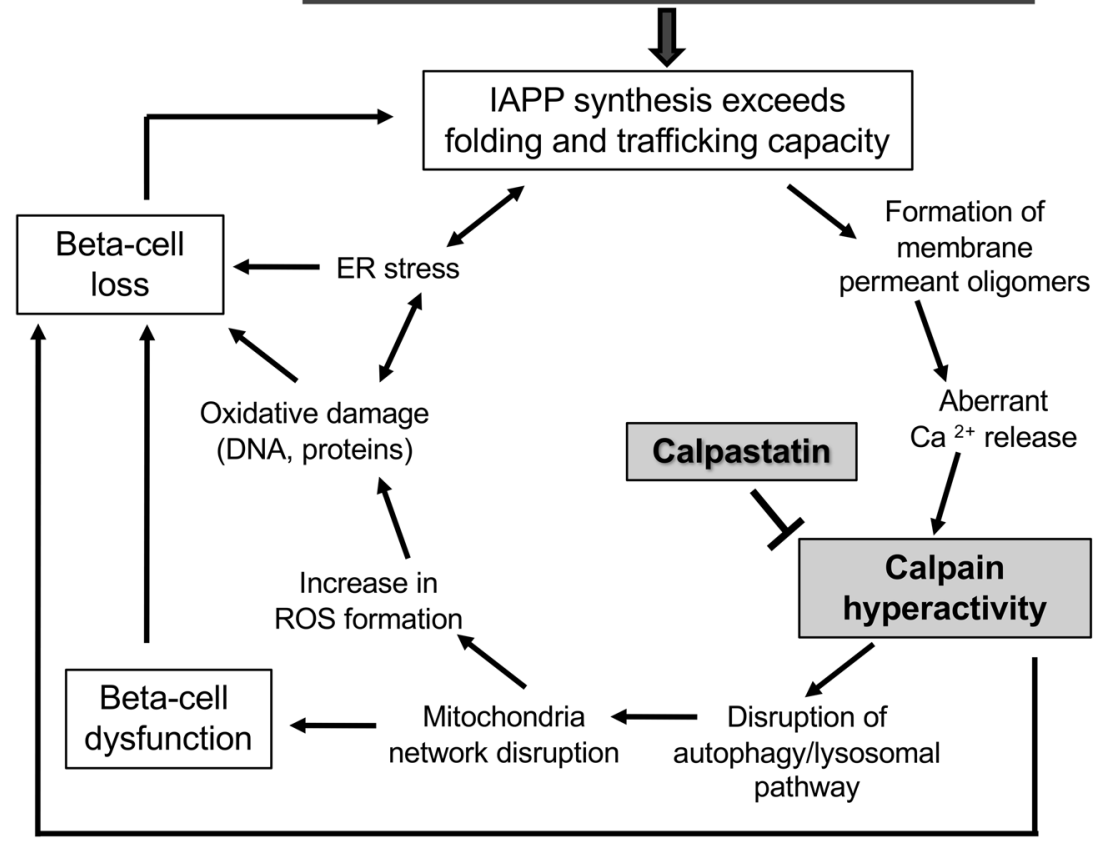

increased ROS formation with oxidative damage, including DNA and proteins. The latter contributes to increased endoplasmic reticulum stress that, in turn, increases hIAPP misfolding and oligomer formation. With sustained endoplasmic reticulum stress, mitochondrial network disruption, and compromised autophagy, the most vulnerable $\beta$ cells undergo apoptosis, leading to an increased burden of hIAPP and insulin synthesis in the remaining more resilient $\beta$ cells. The latter, in turn, reach a threshold for hIAPP synthesis that initiates protein misfolding and oligomer formation that then provokes the adverse cycle, again leading to $\beta$ cell dysfunction and eventually cell death. Once a sufficient number of $\beta$ cells are thus compromised, blood glucose levels begin to increase, further exacerbating $\beta$ cell dysfunction and loss, eventually leading to diabetes. By this model, prevention of calpain hyperactivation in the most vulnerable $\beta$ cells not only avoids the amplification of cellular dysfunction and then loss in the first cells affected, but it retards propagation of this cycle to the other $\beta$ cells and so delays diabetes. While each of the characteristics of $\beta$ cell dysfunction included in the model above have been reported in islets of humans with $\mathrm{T} 2 \mathrm{D}$, and suppression of calpain hyperactivation has been shown to protect human islets from hIAPP toxicity (14), it remains unknown if the antecedent suppression of calpain activity in humans at risk of T2D would be protective, as reported in hIAPP transgenic mice in the current manuscript. In addition, it is possible that calpastatin has effects separate from suppression of calpain activation that may have contributed to $\beta$ cell protection reported here.

The potential therapeutic benefit of suppressing calpain hyperactivation in amyloidogenic protein misfolding diseases has been reported in models of Huntington's, Alzheimer's, and Parkinson's diseases by the same approach of attenuating calpain hyperactivation and is therefore also potentially subject to any unknown off-target beneficial effects of calpastatin $(20,58,59)$. To date, there are no drugs available in humans to suppress calpain hyperactivation, with most available calpain inhibitors being relatively toxic and requiring injection. The development of calpain inhibitors with high specificity and minimal toxicity suitable for use in humans would appear to be a potentially fruitful avenue of therapeutic investigation.

In summary, calpain hyperactivation is established as a proximal cause of $\beta$ cell dysfunction and apoptosis consequent upon hIAPP toxicity, and this toxicity can be substantially overcome by suppression of calpain hyperactivation. This finding adds T2D to Alzheimer's, Parkinson's, and Huntington's diseases as being potentially modifiable by attenuation of calpain hyperactivation.

\section{Methods}

Mice. Animal studies were in compliance with the guidelines of the UCLA Office of Animal Research Oversight. WT FVB mice were originally purchased from Charles River Laboratory, and the colony was maintained at UCLA. The generation of the transgenic mouse expressing human IAPP (FVB- $T g(I A P P)$ $6 \mathrm{Jdm} / \mathrm{Tg}(\mathrm{IAPP}) 6 \mathrm{Jdm}$ or hTG) was described elsewhere (31). The $\beta$ cell-specific transgenic mice expressing full-length human calpastatin under insulin II promoter (castRIP) were a gift of K. Polonsky from the University of Chicago, School of Medicine, Chicago, Illinois, USA (60). First, we backcrossed castRIP mice to FVB background by breeding males to FVB females for 8 generations. Then, castRIP hemizygous males were bred either to homozygous human IAPP transgenic females (hTG to generate homozygous human IAPP transgenic mice hemizygous for human calpastatin (hTG:hCAST) or to FVB females to generate controls (WT:hCAST). Both colonies were maintained as heterozygotes for hCAST by breeding hTG:h- 
CAST and WT:hCAST males to hTG and WT females, respectively, and exhibited normal litter sizes. Mice were maintained at UCLA on a 12-hour-day/night cycle, with Harlan Teklad Rodent Diet 8604 and water ad libitum. Diabetes development was monitored weekly by blood glucose measurements after overnight fast from tail-tip blood sample using a Freestyle Lite blood glucose meter (Abbot). A mouse was considered diabetic if fasting blood glucose levels were equal to or higher than $126 \mathrm{mg} / \mathrm{dl}$ in two consecutive measurements. hTG mice were euthanized by 15 weeks of age due to diabetes. Only male littermates were used in this study.

Islet isolation and protein lysate preparation. Islet isolation was performed as previously described (21). Islets were isolated from 9-week-old nondiabetic mice only to avoid the deleterious effects of elevated glucose. Islets were manually picked, washed twice with ice-cold PBS, incubated for 20 minutes on ice in NP40 lysis buffer (20 mM Tris- $\mathrm{HCl}, 150 \mathrm{mM} \mathrm{NaCl}, 2 \mathrm{mM} \mathrm{MgCl}$, 0.5\% NP-40, $1 \mathrm{mM}$ DTT, $5 \mathrm{mM} \mathrm{NaF}$, $1 \mathrm{mM} \mathrm{Na}_{3} \mathrm{VO}_{4}$, and protease inhibitor cocktail from Sigma-Aldrich (catalog P2714), sonicated, and spun at $10,000 \mathrm{~g}$ at $4^{\circ} \mathrm{C}$ for 10 minutes. Supernatant was stored at $-80^{\circ} \mathrm{C}$ until use for Western blot analysis. We used the NE-PER Nuclear and Cytoplasmic Extraction Kit (Thermo Scientific; Pierce PI-78833) to separate cytoplasmic and nuclear protein fractions of islet lysates. For RNA analysis, islets were preserved in RLT buffer from the RNeasy MiniKit (Qiagen) at $-80^{\circ} \mathrm{C}$ until use. Each sample of islet lysates contained islets pooled from 1 to 2 mice in the case of WT and WT:hCAST groups and islets pooled from 2 to 3 mice in the case of hTG and hTG:hCAST groups.

$R N A$ isolation and analysis. RNA was isolated using the RNA Mini kit (Qiagen) according to the manufacturer's instructions. Single-stranded cDNA was prepared using the Superscript III First-Strand Synthesis System Kit from Invitrogen. Real-time quantitative PCR was performed using FAST SYBRGreen master mix and ABI7900HT or QuantStudio 6 Flex equipments from Applied Biosystems. The following mouse primers were used: Ddit3 (CHOP), gctgcctatacccacatct and cgccttcatccgagaaac; Sqstm1 (p62), gctgcctatacccacatct and cgccttcatccgagaaac; Atg5, aagtctgtccttccgcagtc and tgaagaaagttatctgggtagctca; Nfe2l2, catgatggacttggagttgc and cctccaaaggatgtcaatcaa; Hmoxl, aggctaagaccgccttcc and tgtgttcetctgtcagca; and Nqo1, agcgttcggtattacgat and agtacaatcagggctctt. Ppia (cyclophilin), gtctccttcgagctgtttgc and agccaaatcctttctctcca) was used as a housekeeping gene.

Western blotting. Protein concentration in the lysates was measured using DC protein assay (Bio-Rad). Proteins (20-35 $\mu \mathrm{g}$ per lane) were separated on 4\%-12\% BisTris NuPAGE gels (Life Technologies) and blotted onto a PVDF membrane (Pall). Membranes were blocked in 5\% milk (Bio-Rad), incubated overnight with primary antibodies diluted in the antibody buffer (TBS, $0.1 \%$ Tween $20,5 \%$ BSA), and then probed with horseradish peroxidase-conjugated secondary antibodies from Life Technologies. Proteins were visualized using ECL reagents from Bio-Rad or Millipore. Protein expression levels were quantified using Labworks software (UVP). For detection of cleaved spectrin, proteins (15-30 $\mu \mathrm{g}$ per lane) were separated on 3\%-8\% Tris-Acetate gels from Life Technologies. See complete unedited blots in the supplemental material.

Antibodies and staining kits. The following antibodies were used: rabbit anti-calpastatin (Cell Signaling; 4146, 1:1,000), anti-calpastatin (Santa Cruz; H-300, sc-20779, 1:100 for IF), anti-PARP (Cell Signaling, 9542, 1:1,000), anti-insulin (Cell Signaling, 3014, 1:100 for IF and 1:1,000 for WB), anti-IAPP (Bachem; T4157, 1:1,000), anti-CHOP (GADD-153 [F168], Santa Cruz, sc-575, 1:100 for IF), anti-Bim (clone C34C5, Cell Signaling, 2933, 1:100), anti-P-H2A.X Ser139 (clone 20E3, Cell Signaling, 9718, 1:400), antiLC3B (Cell Signaling, 2775, 1:1,000), and anti-ubiquitin (Cell Signaling, 3933, 1:400); mouse anti-spectrin (Millipore, clone AA6, MAB1622, 1:1,000) and anti-glucagon (Sigma-Aldrich, clone K79bB10, G2654, 1:2000); rat anti-mouse Ki67 (Dako; TEC-3, M7249, 1:50); and guinea pig anti-insulin (Abcam; ab7842, 1:100 for IF and IHC, 1:1,000 for WB) and anti-p62 (Progen Biotechnik; GP62-C, 1:400 for IF and 1:1,000 for WB).

Secondary antibodies for immunofluorescence staining were $\mathrm{F}(\mathrm{ab}$ ')2 conjugates with Cy3, FITC, or Cy5 obtained from The Jackson Laboratories and used at dilution of 1:200. For TUNEL staining, the in situ cell death detection KIT TMR red from Roche Diagnostics Corporation (catalog 12156792910) was used. Slides were mounted with Vectashield with DAPI (Vector Laboratories, H-1200). For insulin peroxidase staining, we used the ABC-VECTASTAIN Standard Kit (PK-4000) and the DAB Peroxidase Substrate Kit (SK-4100) from Vector Laboratories; slides were mounted with Permount (Fisher; SP15-100).

Immunostaining and morphometric analysis. Pancreata were fixed in $4 \%$ PFA overnight at $4^{\circ} \mathrm{C}$ and embedded in paraffin. Staining was performed using $4-\mu \mathrm{m}$ sections following the protocol described in ref. 14. 
For $\beta$ cell mass measurements, pancreatic sections were immunostained for insulin using peroxidase-DAB staining and counterstained with hematoxylin, as described in detail in ref. 35 . The entire pancreatic section was imaged at $\times 40$ magnification ( $\times 4$ objective) using an Olympus IX70 inverted microscope. The insulin-stained area and total section area were quantified using Image Pro Plus software (Image Pro Plus version 5.1.0.20, Media Cybernetics Inc.). $\beta$ Cell mass was calculated as pancreatic insulin positive fractional area multiplied by pancreas weight.

The frequency of $\beta$ cell replication and apoptosis was evaluated in pancreatic sections immunostained for Ki67 and insulin and TUNEL and insulin, respectively. Likewise, the percentage of $\beta$ cells with nuclear translocation of CHOP, double-strand DNA breaks, or cytoplasmic p62 inclusions was determined using pancreatic sections immunostained for insulin and $\mathrm{CHOP}$ or $\mathrm{P}-\mathrm{H} 2 \mathrm{AX}$ or p62, respectively. All islets on the section were viewed using a Leica DM6000 fluorescent microscope with a $\times 20$ objective and imaged using OpenLab 5.5 software (Improvision). 500-2,500 $\beta$ cells (from 15 to 25 islets) were counted per sample. The following criteria were used for determining $\beta$ cell TUNEL, Ki67, CHOP, or P-H2AX positivity: two-thirds or more of the perimeter of the nucleus must be surrounded by insulin and the nuclear contours of the nuclear stain must be in the same plane as DAPI and the insulin staining of the $\beta$ cell in question. Only cells with bright multiple puncta in the nucleus or diffuse nuclear staining brighter than the nuclei of the surrounding endocrine and exocrine background staining were considered to be positive for P-H2AX. The frequency was expressed as percentage of $\beta$ cells expressing the marker of interest. Image analysis was performed blindly by two independent investigators (TG and AEB).

Statistics. Data are presented as mean \pm SEM from $n$ independent experiments. Statistical analysis was performed using 2-tailed Student's $t$ test to compare two groups (as indicated in figure legends) or by 1-way ANOVA followed by Fisher's LSD post-hoc test for multiple group comparison using Statistica (Statsoft). A value of $P<0.05$ was considered statistically significant.

Study approval. Present studies in animals were reviewed and approved by the Office of Animal Research Oversight, UCLA.

\section{Author contributions}

TG designed research studies, performed and analyzed research, and wrote the manuscript and the final submitted version; SC contributed to performance of experiments, data analysis, and writing the final submitted version; JDH performed experiments and contributed to image analysis; JFR contributed to performance of experiments; AEB contributed to image analysis; and PCB designed research studies and wrote the manuscript and its final submitted version.

\section{Acknowledgments}

We thank Bonnie Lui for excellent editorial assistance in preparing the manuscript; Chang Liu, Rosibel Hernandez, Bonnie Yeh, Ana Gademzadeheskandari, and Johanna Park for their excellent technical assistance; and Megan Cory for help with image analysis. We thank K Polonsky, University of Chicago, for the gift of the $\beta$ cell-specific calpastatin transgenic mice. Funding for these studies was from NIH/National Institute of Diabetes and Digestive and Kidney Diseases grant DK059579 and Larry Hillblom Foundation grant 2014-D-001-NET.

Address correspondence to: Peter C. Butler, Larry L. Hillblom Islet Research Center, UCLA David Geffen School of Medicine, 900 Veteran Avenue, 24-130 Warren Hall, Los Angeles California 90095-7073, USA. Phone: 310.794.7645; E-mail: pbutler@mednet.ucla.edu.

1. Butler AE, Janson J, Bonner-Weir S, Ritzel R, Rizza RA, Butler PC. Beta-cell deficit and increased beta-cell apoptosis in humans with type 2 diabetes. Diabetes. 2003;52(1):102-110.

2. Haataja L, Gurlo T, Huang CJ, Butler PC. Islet amyloid in type 2 diabetes, and the toxic oligomer hypothesis. Endocr Rev. 2008;29(3):303-316

3. Westermark P, Andersson A, Westermark GT. Islet amyloid polypeptide, islet amyloid, and diabetes mellitus. Physiol Rev. 2011;91(3):795-826

4. Soeller WC, et al. Islet amyloid-associated diabetes in obese A(vy)/a mice expressing human islet amyloid polypeptide. Diabetes. 1998;47(5):743-750

5. Butler AE, Jang J, Gurlo T, Carty MD, Soeller WC, Butler PC. Diabetes due to a progressive defect in beta-cell mass in rats transgenic for human islet amyloid polypeptide (HIP Rat): a new model for type 2 diabetes. Diabetes. 2004;53(6):1509-1516. 
6. Wagner JD, Carlson CS, O'Brien TD, Anthony MS, Bullock BC, Cefalu WT. Diabetes mellitus and islet amyloidosis in cynomolgus monkeys. Lab Anim Sci. 1996;46(1):36-41.

7. Henson MS, O'Brien TD. Feline models of type 2 diabetes mellitus. ILAR J. 2006;47(3):234-242.

8. Janson J, Ashley RH, Harrison D, McIntyre S, Butler PC. The mechanism of islet amyloid polypeptide toxicity is membrane disruption by intermediate-sized toxic amyloid particles. Diabetes. 1999;48(3):491-498.

9. Kegulian NC, et al. Membrane Curvature-sensing and Curvature-inducing Activity of Islet Amyloid Polypeptide and Its Implications for Membrane Disruption. J Biol Chem. 2015;290(43):25782-25793.

10. Gafni J, Ellerby LM. Calpain activation in Huntington's disease. J Neurosci. 2002;22(12):4842-4849.

11. Chan SL, Culmsee C, Haughey N, Klapper W, Mattson MP. Presenilin-1 mutations sensitize neurons to DNA damage-induced death by a mechanism involving perturbed calcium homeostasis and activation of calpains and caspase-12. Neurobiol Dis. 2002;11(1):2-19.

12. Cao G, et al. Critical role of calpain I in mitochondrial release of apoptosis-inducing factor in ischemic neuronal injury. $J$ Neurosci. 2007;27(35):9278-9293.

13. Samantaray S, Ray SK, Banik NL. Calpain as a potential therapeutic target in Parkinson's disease. CNS Neurol Disord Drug Targets. 2008;7(3):305-312.

14. Huang CJ, et al. Calcium-activated calpain-2 is a mediator of beta cell dysfunction and apoptosis in type 2 diabetes. $J$ Biol Chem. 2010;285(1):339-348.

15. Ferreira A. Calpain dysregulation in Alzheimer's disease. ISRN Biochem. 2012;2012:728571.

16. D'Orsi B, et al. Calpains are downstream effectors of bax-dependent excitotoxic apoptosis. J Neurosci. 2012;32(5):1847-1858.

17. Lu S, et al. A calcium-dependent protease as a potential therapeutic target for Wolfram syndrome. Proc Natl Acad Sci U S A. 2014;111(49):E5292-E5301.

18. Sorimachi H, Ishiura S, Suzuki K. Structure and physiological function of calpains. Biochem J. 1997;328 (Pt 3):721-732.

19. Williams A, et al. Novel targets for Huntington's disease in an mTOR-independent autophagy pathway. Nat Chem Biol. 2008;4(5):295-305.

20. Menzies FM, et al. Calpain inhibition mediates autophagy-dependent protection against polyglutamine toxicity. Cell Death Differ. 2015;22(3):433-444.

21. Rivera JF, Costes S, Gurlo T, Glabe CG, Butler PC. Autophagy defends pancreatic $\beta$ cells from human islet amyloid polypeptide-induced toxicity. J Clin Invest. 2014;124(8):3489-3500.

22. Shigihara N, et al. Human IAPP-induced pancreatic $\beta$ cell toxicity and its regulation by autophagy. J Clin Invest. 2014;124(8):3634-3644.

23. Kim J, et al. Amyloidogenic peptide oligomer accumulation in autophagy-deficient $\beta$ cells induces diabetes. J Clin Invest. 2014;124(8):3311-3324.

24. Masini M, et al. Autophagy in human type 2 diabetes pancreatic beta cells. Diabetologia. 2009;52(6):1083-1086.

25. Schneider JL, Cuervo AM. Autophagy and human disease: emerging themes. Curr Opin Genet Dev. 2014;26:16-23.

26. Kiriyama Y, Nochi H. The function of autophagy in neurodegenerative diseases. Int J Mol Sci. 2015;16(11):26797-26812.

27. Gurlo T, et al. Evidence for proteotoxicity in beta cells in type 2 diabetes: toxic islet amyloid polypeptide oligomers form intracellularly in the secretory pathway. Am J Pathol. 2010;176(2):861-869.

28. Kayed R, et al. Common structure of soluble amyloid oligomers implies common mechanism of pathogenesis. Science. 2003;300(5618):486-489.

29. Yamashima T. Reconsider Alzheimer's disease by the 'calpain-cathepsin hypothesis'--a perspective review. Prog Neurobiol. 2013;105:1-23.

30. Rao MV, et al. Marked calpastatin (CAST) depletion in Alzheimer's disease accelerates cytoskeleton disruption and neurodegeneration: neuroprotection by CAST overexpression. J Neurosci. 2008;28(47):12241-12254.

31. Janson J, et al. Spontaneous diabetes mellitus in transgenic mice expressing human islet amyloid polypeptide. Proc Natl Acad Sci U S A. 1996;93(14):7283-7288

32. Giorgi C, De Stefani D, Bononi A, Rizzuto R, Pinton P. Structural and functional link between the mitochondrial network and the endoplasmic reticulum. Int J Biochem Cell Biol. 2009;41(10):1817-1827.

33. Paillusson S, et al. There's Something Wrong with my MAM; the ER-Mitochondria Axis and Neurodegenerative Diseases. Trends Neurosci. 2016;39(3):146-157.

34. Huang CJ, et al. High expression rates of human islet amyloid polypeptide induce endoplasmic reticulum stress mediated betacell apoptosis, a characteristic of humans with type 2 but not type 1 diabetes. Diabetes. 2007;56(8):2016-2027.

35. Gurlo T, et al. CHOP contributes to, but is not the only mediator of, IAPP induced $\beta$-cell apoptosis. Mol Endocrinol. 2016;30(4):446-454

36. Loboda A, Damulewicz M, Pyza E, Jozkowicz A, Dulak J. Role of Nrf2/HO-1 system in development, oxidative stress response and diseases: an evolutionarily conserved mechanism. Cell Mol Life Sci. 2016;73(17):3221-3247.

37. Tornovsky-Babeay S, et al. Type 2 diabetes and congenital hyperinsulinism cause DNA double-strand breaks and p53 activity in $\beta$ cells. Cell Metab. 2014;19(1):109-121.

38. Wooten MW, et al. Signaling, polyubiquitination, trafficking, and inclusions: sequestosome 1/p62's role in neurodegenerative disease. J Biomed Biotechnol. 2006;2006(3):62079.

39. Rivera JF, et al. Human-IAPP disrupts the autophagy/lysosomal pathway in pancreatic $\beta$-cells: protective role of p62-positive cytoplasmic inclusions. Cell Death Differ. 2011;18(3):415-426.

40. Kabeya Y, Mizushima N, Yamamoto A, Oshitani-Okamoto S, Ohsumi Y, Yoshimori T. LC3, GABARAP and GATE16 localize to autophagosomal membrane depending on form-II formation. J Cell Sci. 2004;117(Pt 13):2805-2812.

41. Mizushima N, et al. A protein conjugation system essential for autophagy. Nature. 1998;395(6700):395-398

42. Costes $\mathrm{S}$, et al. $\beta$-cell dysfunctional ERAD/ubiquitin/proteasome system in type 2 diabetes mediated by islet amyloid polypeptide-induced UCH-L1 deficiency. Diabetes. 2011;60(1):227-238.

43. Doody RS, et al. Phase 3 trials of solanezumab for mild-to-moderate Alzheimer's disease. N Engl J Med. 2014;370(4):311-321.

44. Gregersen N, Bross P. Protein misfolding and cellular stress: an overview. Methods Mol Biol. 2010;648:3-23. 
45. Kar P, Samanta K, Shaikh S, Chowdhury A, Chakraborti T, Chakraborti S. Mitochondrial calpain system: an overview. Arch Biochem Biophys. 2010;495(1):1-7.

46. Esteves AR, Arduíno DM, Swerdlow RH, Oliveira CR, Cardoso SM. Dysfunctional mitochondria uphold calpain activation: contribution to Parkinson's disease pathology. Neurobiol Dis. 2010;37(3):723-730.

47. Giacomello M, Drago I, Pizzo P, Pozzan T. Mitochondrial Ca2+ as a key regulator of cell life and death. Cell Death Differ. 2007;14(7):1267-1274

48. Bhola PD, Letai A. Mitochondria-Judges and Executioners of Cell Death Sentences. Mol Cell. 2016;61(5):695-704.

49. Luo S, et al. Bim inhibits autophagy by recruiting Beclin 1 to microtubules. Mol Cell. 2012;47(3):359-370.

50. Pralong WF, Bartley C, Wollheim CB. Single islet beta-cell stimulation by nutrients: relationship between pyridine nucleotides, cytosolic Ca2+ and secretion. EMBO J. 1990;9(1):53-60.

51. Robertson RP, Harmon JS. Diabetes, glucose toxicity, and oxidative stress: A case of double jeopardy for the pancreatic islet beta cell. Free Radic Biol Med. 2006;41(2):177-184

52. Back SH, Kaufman RJ. Endoplasmic reticulum stress and type 2 diabetes. Annu Rev Biochem. 2012;81:767-793.

53. Costes S, Langen R, Gurlo T, Matveyenko AV, Butler PC. $\beta$-Cell failure in type 2 diabetes: a case of asking too much of too few? Diabetes. 2013;62(2):327-335.

54. Meier JJ, et al. Beta-cell replication is the primary mechanism subserving the postnatal expansion of beta-cell mass in humans. Diabetes. 2008;57(6):1584-1594.

55. Saisho Y, Butler AE, Manesso E, Elashoff D, Rizza RA, Butler PC. $\beta$-cell mass and turnover in humans: effects of obesity and aging. Diabetes Care. 2013;36(1):111-117.

56. Kushner JA. The role of aging upon $\beta$ cell turnover. J Clin Invest. 2013;123(3):990-995.

57. Anello M, et al. Functional and morphological alterations of mitochondria in pancreatic beta cells from type 2 diabetic patients Diabetologia. 2005;48(2):282-289.

58. Vaisid T, Barnoy S, Kosower NS. Calpastatin overexpression attenuates amyloid-beta-peptide toxicity in differentiated PC12 cells. Neuroscience. 2008;156(4):921-931.

59. Diepenbroek M, et al. Overexpression of the calpain-specific inhibitor calpastatin reduces human alpha-Synuclein processing, aggregation and synaptic impairment in [A30P] SSyn transgenic mice. Hum Mol Genet. 2014;23(15):3975-3989.

60. Johnson JD, et al. RyR2 and calpain-10 delineate a novel apoptosis pathway in pancreatic islets. J Biol Chem. 2004;279(23):24794-24802. 